\title{
STREPTOCOCCUS GALLOLYTICUS INFECTION IN PIGEONS: PATHOGENICITY AND ANTIBIOTIC SUSCEPTABILITY
}

\author{
HASSAN, H.KH. \\ Dept. of Poultry Diseases, Animal Health Research Instiute, Assiut, Egypt. \\ Email: hassankhali122@yahoo.com
}

\section{ABSTRACT}

Received at: $23 / 9 / 2014$

Accepted: 11/11/2014
Streptococcus gallolyticus infection is considered an important septicemic disease in pigeons especially in squabs. In this study the pathogenicity and antimicrobial sensitivity of St. gallolyticus were searched. 141 samples of diseased and recently dead pigeons of different ages were collected and subjected to bacterial examination in order to isolate St. gallolyticus. Sixteen strains were isolated and identified at recovery rate of $11.35 \%$. All isolated strains found following biotype I. The strains were tested In-Vitro for antimicrobial sensitivity to 9 types of antimicrobial drugs. All strains were found highly sensitive to enrofloxacin and flumequine, followed by streptomycin and florophenicol then doxycyclin and lincomycin. A half of strains were sensitive to trimethoprim / sulphmethoxazole, while most strains show high resistance to ampicillin and erythromycin. The test indicates that, most isolated strains $(11 / 16)$ have multidrug resistance. Experimental infection with a strain of St. gallolyticus was studied by 2 routs (Intravenous inoculation or crop inoculation) in clinically healthy pigeons. The inoculated microbe dose not cause deaths by any of the 2 routs used for inoculation. Clinical signs as well as post-mortem lesions of experimentally inoculated pigeons by both two routes were recorded and discussed. The inoculated organism was re-isolated from inoculated birds.

Key words: Streptococcus, Gallolyticus, Pigeons, Antibiotic susceptability.

\section{INTRODUCTION}

Streptococcosis is an important septicaemic disease in pigeons, it is caused by Streptococcus gallolyticus which was formerly identified as St. bovis (Devriese et al., 1990b; De Herdt et al., 1994a and Devriese et al., 1998).

Madej, (1961) described an outbreaks of streptococccal disease in five small breeding lofts in Polish.

Devriese et al. (1990a) isolated St. gallolyticus strains from different lesions in pigeons. St. gallolyticus was only infrequently found in the gut and faeces of pigeons without streptococcal disease. It was also isolated from the crop and the pharynx of a minority of healthy pigeons. They mentioned that, St. gallolyticus infection in pigeons is an unusual finding because St. gallolyticus appears to be rare in other birds. It was not found in the faeces of wild birds (Mundt, 1963) or in the caeca of chickens (Barnes, 1958) or turkeys (Harrison and Hansen, 1950). St. gallolyticus is an important component of the intestinal flora of many mammals, especially farm animals and less often of humans. St. gallolyticus (St.bovis) can act as a pathogen and may be involved in septicaemic disease and endocarditis in man and ruminants (Parker, 1978). Chadfield et al. (2007) investigated an outbreak of St. gallolyticus in a broiler flock. These investigations also demonstrated a clear heterogeneity with pigeon isolates.

De Herdt et al. (1992a) and Vanrobaeys et al. (1996) reported that, different types have been recognized within the St. gallolyticus species in healthy pigeons and pigeons that died from septicemia in equal frequency (five biotypes, two sub-biotypes, five serotypes and six supernatant-phenotypes). This indicates that St. gallolyticus is a facultative pathogen which can belong to the intestinal flora of healthy pigeons. The conditions leading to septicemia and disease are unknown.

Devriese et al. (1990b) mentioned that, streptococcal septicaemia, is known to exist in pigeons, mainly in squabs, commonly the disease was peracute or acute 
and rarely chronic. The mortality rate in untreated pigeons reached $78 \%$ and was highest in short-beak pigeons of Belgian race. Pure cultures of Streptococci were isolated from the parenchymatous organs and the blood in the majority of the cases. They diagnosed St. gallolyticus infection in 20 pigeon lofts submitted for post mortem investigation. Clinical signs were variable and ranged from hyperacute death to chronic lameness with arthritis. Lesions were generally unspecific except for single cases of muscle necrosis with purulent myositis. They found that, St. gallolyticus infection was an important etiology ranking next to Salmonella. Intravenous inoculations of St. gallolyticus resulted in prostration, long lasting loss of weight and polyuria. After oral inoculation no clinical signs were seen.

St. gallolyticus has been reported with septicemia in pigeons and is associated with significant lesions including extensive areas of multifocal necrosis in different organs (Devriese et al., 1990a; De Herdt et al., 1992b; De Herdt et al., 1994a).

De Herdt et al. (1994b) described the most important clinical signs of St. gallolyticus septicaemia that include inability to fly, lameness, emaciation, polyuria and production of slimy, green droppings, and it may result in sudden death in pigeons of all ages. Also, They studied the prevalence of St. gallolyticus in 1056 pigeons. The microbe was isolated from the organs or joints of 106 pigeons (10 $\%)$. Other bacterial pathogens were not isolated from the samples that were positive for S. gallolyticus.

Van der Toorn and Lumeij, (2001) stated that, St. gallolyticus, formerly known as St. bovis is known since 1988 as a facultative pathogen of racing pigeons. In one study, St. gallolyticus septicaemia was diagnosed in $10 \%$ of necropsied pigeons. Since St. gallolyticus was also isolated from nearly $40 \%$ of clinical healthy pigeons, it is regarded as a facultative pathogen. Experimentally ampicillin, doxycycline and erythromycin have shown therapeutic effects. For the treatment of clinical cases the use of ampicillin is advocated, together with hygienic measures, such as the use of grid floors and avoiding overcrowding.

De Herdt et al. (1993) studied antibiotic susceptibility pattern of St. gallolyticus isolated from pigeons in vitro. St. gallolyticus strains were sensitive to penicillins, macrolides, lincomycin, tetracyclines, chloramphenicol and nitrofurans. However, the prevalence of acquired resistance against tetracyclines was approximately $40 \%$. Sulphonamides and trimethoprim had little activity against St. gallolyticus while activity of the quinolone enrofloxacin and the aminoglycoside antibiotics, neomycin and gentamicin were in or near to the intermediate range. The comparative efficacy of 5 antimicrobials administered via the drinking water for the treatment of experimental St. gallolyticus infection in pigeons was also tested. Morbidity after intravenous inoculation of St. gallolyticus in groups of pigeons treated with ampicillin, erythromycin, doxycycline, enrofloxacin and trimethoprim was $20 \%, 30 \%, 20 \%, 70 \%$ and $90 \%$, respectively. Morbidity in an untreated control group was $90 \%$.

Kimpe et al. (2002a) reported that, little information is available on antimicrobial resistance in pigeon pathogens. They studied the susceptibility of thirtythree St. gallolyticus strains isolated from internal organs of homing pigeons (Columba livia) to the antimicrobials that is most commonly used to treat pigeons. Aminoglycosides (gentamicin and kanamycin), trimethoprim and flumequine were relatively inactive against the tested streptococci. Acquired tetracycline resistance amounted to $85 \%$, and lincomycin and macrolide (erythromycin) resistance to $48 \%$ and $45 \%$, respectively, all erythromycin-resistant strains, except one, were also resistance to lincomycin. Fluoroquinolone (enrofloxacin) resistance was found in four St. gallolyticus strains. All strains were susceptible to ampicillin.

As far as Egypt is concerned, Mohamed and Abd ElMotelib, (2007) were able to isolate St. gallolyticus from $22.5 \%$ of healthy and diseased pigeons. Intravenous inoculation showed signs of inappitance, loss of weight, slimy green drops and shivering and post-mortem lesions of airsacculitis, liver abscess, mottled pancreas and spleen, ulcers and gasses in intestine, nephritis and distended heart. Orally inoculation showed signs of depression, inability to fly, loss of body weight, slimy green drops and lameness and with post-mortem lesions of congested lungs, flaccid heart, mottled pancreas, congested liver, spleen and kidneys, enteritis and arthritis in hock joint. The auther noticed that, St. gallolyticus isolates were highly sensitive to ampicillin, enrofloxacin, erythromycin, sensitive to gentamycin, neomycin, penicillin, less sensitve to chloramphenicol, tetracycline and resistant to lincomycin and trimethoprim. Mohamed et al. (2009) were successful in isolation St. gallolyticus with ratio of $21.4 \%$ from the examined pigeons.

The present study was designed to investigate the incidence of St. gallolyticus in homing pigeons, antimicrobial drug sensitivity In Vitro to detect the most effective drugs on these isolates and to detect the pathological effects of this pathogen on healthy pigeons during experimental infection. 


\section{MATERIALS and METHODS}

\section{* Samples:}

Specimens from liver, heart, kidneys, spleen and joints of 141 diseased or recently dead homing pigeons that expressed affection in these organs were collected for bacteriological examination to study the prevalence of St. gallolyticus.

\section{* Bacteriological examination:}

Samples were inoculated onto Slanetz and Bartley (S\&B) Agar, Columbia Agar (Oxoid, Basingstoke, England) or Columbia CAN (colistine and nalidixic acid) agar (Gibco, Paisley, Scotland) with $5 \%$ bovine blood and Brillant Green Agar as described by Devriese et al. (1998). Cultures on S\&B Agar and Columbia Agar were incubated for $24 \mathrm{~h}$ at $37^{\circ} \mathrm{C}$ in an atmosphere enriched with $5 \% \mathrm{CO}_{2}$. Brillant Green Agar plates were incubated aerobically at $37^{\circ} \mathrm{C}$. Uniformly pink colonies on S\&B Agar were tested for resistance to $\mathrm{NaCl}$ by inoculation in Brain Heart Infusion broth (Oxoid) with $6.5 \% \mathrm{NaCl}$ and for resistance to bile on Bile Aesculin Agar (Difco, Detroit, USA). Amylase production was tested by spot inoculation on Mueller Hinton Agar (Difco) or on Columbia Agar base in which the starch content was increased to $1.5 \%$. The plates were flooded with iodine solution after overnight incubation. Ability to grow anaerobically on Rogosa Agar (Oxoid) in a $\mathrm{H}_{2}$ and $\mathrm{CO}_{2}$ atmosphere (Gaskit, Oxoid) was investigated. Haemolysis was looked for on Columbia Agar with ox blood. All strains were identified biochemically without difficulty as St. gallolyticus according to (Devriese et al., 1990a, Devriese et al., 1993 and Devriese et al., 1998). Biotyping identification was made as described by De Herdt et al. (1992a). For preservation, isolates were stored frozen on brain heart infusion broth with $30 \%$ glycrole at $-20^{\circ} \mathrm{C}$ according to Baele et al. (2002).

\section{*Antimicrobial susceptibility pattern of St. gallolyticus strains isolated from pigeons:}

In- vitro antimicrobial susceptibility determination was tested by the single-disc diffusion method. Muller-Hinton agar (Oxoid, Basingstoke, UK) was prepared in a uniform thickness $(4 \mathrm{~mm})$ for testing of St. gallolyticus isolates. The St. gallolyticus strains were tested against 9 antimicrobial agents (Bioanalyse - Turky) including: ampicillin $(10 \mu \mathrm{g})$, florophenicol $(30 \mu \mathrm{g})$, doxycycline $(30 \mu \mathrm{g})$, erythromycin $(15 \mu \mathrm{g})$, lincomycin $(10 \mu \mathrm{g})$, enrofloxacin $\left(\begin{array}{ll}10 & \mu \mathrm{g}\end{array}\right)$, streptomycin $(10 \mu \mathrm{g})$, flumequine $(30 \mu \mathrm{g})$ and trimethoprimsulphamethoxazole $\quad(1.25 \mu \mathrm{g} \quad / 23.75 \quad \mu \mathrm{g})$. The diameters of the zones of inhibition were interpreted by referring to the table which represents the
NCCLS subcommittee's recommendation (NCCLS, 2001).

\section{* Experimental infections:}

* Birds: 30 clinically healthy pigeons at 4 to 12 months old, free of bacterial diseases, vaccinated against Paramyxovirus 1 were collected from different owners to use in experimental infection. Two groups (10 birds for each group plus 5 birds for each group as control) were formed. Each group was housed separately in wire floored cages and received water and food ad libitum.

*Preparation of inoculum: A strain of St. gallolyticus was grown overnight on Columbia blood agar and suspensions with a density of 0.5 McFarland scale was prepared in buffered physiological saline. The pigeons received $0.5 \mathrm{ml}$ $\mathrm{I} / \mathrm{V}$ containing $3.5 \times 10^{7}$ colony forming units (cfu) according to Kimpe et al. (2003). The orally infected birds received in the crop $2 \mathrm{ml}$ of a fully grown overnight Brain Heart Infusion broth (Oxoid) culture containing $1 \times 10^{8} \mathrm{cfu}$ as described by Devriese et al. (1990b).

*Experimental desigen: Ten pigeons were inoculated intravenously (I/V) with St. gallolyticus strain. The strain was also used in a second experiment in which ten pigeons were inoculated orally. Two of 5 pigeons control groups, one injected $\mathrm{I} / \mathrm{V}$ by $0.5 \mathrm{ml}$ of sterile saline and kept as control for $\mathrm{I} / \mathrm{V}$ inoculated group. The other control group of orally inoculated group was received $2 \mathrm{ml}$ of sterile saline orally. Swabs from the droppings and the throats were inoculated onto Slanetz and Bartley agar in order to detect St. gallolyticus carriage and excretion for re-isolation the pathogen and also from heart of necropised pigeons. The birds were observed for deaths, clinical signs, and lesions. At days 7, 14, 21, 28, and 35 pos-inoculation 2 birds from each group plus one from its control were necropised after slaughtering for observing lesions in internal organs.

\section{RESULTS}

\section{* Identification of St. gallolyticus strains:}

Sixteen strains of St. gallolyticus were isolated from infected homing pigeons. All St. gallolyticus strains appear as uniformly pink colonies on S\&B Agar (Fige,1), grow on Bile Aesculin Agar and blackened this medium. None was able to grow in $6.5 \% \mathrm{NaCl}$. They produced a very characteristic strong amylase reaction (Fig., 2) and were able to grow anaerobically on Rogosa agar. They were not haemolytic. The biochemical characteristics of the strains were typical of the species St. gallolyticus. All isolated strains found following biotype I. 
Assiut Vet. Med. J. Vol. 60 No. 143 October 2014

Table 1: Incidence of St. gallolyticus isolation in naturally infected pigeons.

\begin{tabular}{lccccc}
\hline \multicolumn{2}{c}{ Adult pigeons } & \multicolumn{2}{c}{ Pigeon squabs } & \multicolumn{2}{c}{ Total pigeons } \\
\hline No. & $\%$ & No. & $\%$ & No. & $\%$ \\
\hline $3 / 32$ & 9.38 & $13 / 109$ & 11.93 & $16 / 141$ & 11.35 \\
\hline
\end{tabular}

Table 2: Incidence of St. gallolyticus isolates in relation to status of homing pigeons. ( $\mathrm{n}=141)$

\begin{tabular}{ccccccc}
\hline \multirow{2}{*}{ Case } & \multicolumn{2}{c}{ Adults } & \multicolumn{2}{c}{ Squabs } & \multicolumn{2}{c}{ Total } \\
\cline { 2 - 7 } & $\begin{array}{c}\text { No. of } \\
+\mathrm{ve}\end{array}$ & $\begin{array}{c}\text { No. of } \\
+\mathrm{ve}\end{array}$ & $\begin{array}{c}\text { No. of } \\
+\mathrm{ve}\end{array}$ & $\%$ \\
\hline Diseased & 3 & 2.13 & 4 & 2.84 & 7 & 4.97 \\
\hline Dead & 0 & 0 & 9 & 6.38 & 9 & 6.38 \\
\hline Total & 3 & 2.13 & 13 & 9.22 & 16 & 11.35 \\
\hline
\end{tabular}

Table 3: In-Vitro antimicrobial sensitivity of St. gallolyticus isolates.

\begin{tabular}{lcc}
\hline Antimicrobial agent (9) & \multicolumn{2}{c}{ No. and \% of sensitive \& resistant strains(n = 16) } \\
\cline { 2 - 3 } & Sensitive & Resistant \\
\hline Ampicillin & $2(12.5 \%)$ & $14(87.5 \%)$ \\
Florophenicol & $13(81.3 \%)$ & $3(18.7)$ \\
Doxycycline & $12(75 \%)$ & $4(25 \%)$ \\
Erythromycin & $2(12.5 \%)$ & $14(87.5 \%)$ \\
Flumequine & $16(100 \%)$ & $0(0 \%)$ \\
Lincomycin & $12(75 \%)$ & $4(25 \%)$ \\
Enrofloxaclin & $16(100 \%)$ & $0(0 \%)$ \\
Trimethoprim/ Sulfamethoxazole & $8(50 \%)$ & $8(50 \%)$ \\
Streptomycin & $13(81.3 \%)$ & $3(18.75 \%)$ \\
\hline
\end{tabular}

Table 4: Antimicrobial resistance pattern of St. gallolyticus $(\mathrm{n}=61)$.

\begin{tabular}{lcc}
\hline \multicolumn{1}{c}{ Antimicrobial resistance } & $\begin{array}{c}\text { No. of sensitive } \\
\text { strains }\end{array}$ \\
\hline Enro., Flu., Floro., Str., Linc.,Dox., STX, Amp., Ery. & (Resist 0 antibiotics) & 2 \\
Enro., Flu., Floro., Str., Linc.,Dox., STX. & (Resist 2 antibiotics) & 3 \\
Enro., Flu., Floro., Str., Linc.,Dox & (Resist3 antibiotics) & 5 \\
Enro., Flu., Floro., Linc.,Dox. & (Resist 4 antibiotics) & 3 \\
Enro., Flu., Str., STX. & (Resist 5 antibiotics) & 3 \\
\hline
\end{tabular}

Enro.= Enrofloxacin, Flu. $=$ Flumequine, Floro. $=$ Florophenicol, Str. $=$ Streptomycin, Linc. $=$ Lincomycin, Dox. $=$ Doxycycllin, STX = trimethoprim $/$ Sulfamethoxazole, Amp. = Ampicillin and Ery. $=$ Erythromycin. 
Table 5: Experimental infection using St. gallolyticus.

\begin{tabular}{|c|c|c|c|c|c|c|c|}
\hline Experiment & $\begin{array}{l}\text { No. of } \\
\text { birds }\end{array}$ & Dose & Time & $\begin{array}{l}\text { Clinical signs } \\
\text { post } \\
\text { inoculation }\end{array}$ & $\begin{array}{l}\text { Post mortem } \\
\text { lesions }\end{array}$ & Mortality & $\begin{array}{c}\text { Re-isolation of St. gallolyticus post- } \\
\text { inoculation }\end{array}$ \\
\hline
\end{tabular}

Groups

\begin{tabular}{|c|c|c|c|c|c|c|c|c|c|c|c|}
\hline & & & & & & & $\begin{array}{c}7 \\
\text { days }\end{array}$ & $\begin{array}{c}14 \\
\text { days }\end{array}$ & $\begin{array}{c}21 \\
\text { days }\end{array}$ & $\begin{array}{c}28 \\
\text { days }\end{array}$ & $\begin{array}{c}35 \\
\text { days }\end{array}$ \\
\hline \multirow[t]{2}{*}{ Controls } & $\begin{array}{c}10(5 \mathrm{I} / \mathrm{V} \\
\text { and } 5 \\
\text { orally })\end{array}$ & $\begin{array}{c}0.5 \mathrm{ml} \text { of } \\
3.5 \times 10^{7} \\
\text { sterile } \\
\text { saline } \mathrm{I} / \mathrm{V} \\
\text { or } 2 \mathrm{ml} \text { of } \\
1 \times 10^{8}\end{array}$ & $\begin{array}{c}35 \\
\text { days. }\end{array}$ & $\begin{array}{l}\text { No clinical } \\
\text { signs of } \\
\text { disease. }\end{array}$ & $\begin{array}{l}\text { No gross } \\
\text { lesions }\end{array}$ & $\begin{array}{c}\text { No } \\
\text { mortality }\end{array}$ & for & for & for & for & $\begin{array}{l}\text {-ve } \\
\text { for }\end{array}$ \\
\hline & & $\begin{array}{l}\text { sterile } \\
\text { saline } \\
\text { orally }\end{array}$ & & & & & all & all & all & all & all \\
\hline $\begin{array}{c}\text { I/V } \\
\text { inoculation }\end{array}$ & 10 & $\begin{array}{l}0.5 \mathrm{ml} \text { of } \\
\begin{array}{c}3.5 \times 10^{7} \\
\mathrm{cfu}\end{array}\end{array}$ & $\begin{array}{c}35 \\
\text { days }\end{array}$ & $\begin{array}{c}\text { Ruffled } \\
\text { feathers, loss } \\
\text { of weights, } \\
\text { wing drop } \\
\text { (Fig., 3), } \\
\text { greenish } \\
\text { white } \\
\text { diarrhea and } \\
\text { polyurea }\end{array}$ & $\begin{array}{l}\text { Cloudy air-sacs } \\
\text { (Fig., 3) } \\
\text { hepatitis, } \\
\text { enteritis, } \\
\text { kidneys are } \\
\text { enlarged in } \\
\text { some birds } \\
\text { (Fig., 5) and } \\
\text { atrophied in } \\
\text { others. round } \\
\text { shape heart. } \\
\text { (Fig., 6) }\end{array}$ & $\begin{array}{l}\text { No } \\
\text { mortality }\end{array}$ & +ve C. & +ve C. & +ve C, & +ve C. & $\begin{array}{l}\text {-ve T, } \\
\text {-ve C. }\end{array}$ \\
\hline \multirow[t]{3}{*}{$\begin{array}{l}\text { Oral (crop) } \\
\text { inoculation }\end{array}$} & 10 & $\begin{array}{c}2 \mathrm{ml} \text { of } \\
1 \times 10^{8} \mathrm{cfu}\end{array}$ & $\begin{array}{c}35 \\
\text { days }\end{array}$ & $\begin{array}{l}\text { Ruffled } \\
\text { feathers on } \\
\text { some birds. } \\
\text { very slight } \\
\text { loss in } \\
\text { weight in } \\
\text { two birds. }\end{array}$ & $\begin{array}{l}\text { Cloudy air- } \\
\text { sacs in one } \\
\text { bird and no } \\
\text { other signs. }\end{array}$ & $\begin{array}{l}\text { No } \\
\text { mortality }\end{array}$ & +veT, & +veT, & -ve T, & -ve T, & -ve T, \\
\hline & & & & & & & $+\mathrm{veC}$ & $+\mathrm{veC}$ & $+v e C$ & -ve C, & -ve C, \\
\hline & & & & & & & -ve H. & -ve H. & -ve H. & -ve H & -ve H \\
\hline
\end{tabular}

$\mathrm{I} / \mathrm{V}=$ Intravenous, $\mathrm{T}=$ throat, $\mathrm{C}=$ Cloacae and $\mathrm{H}=$ Heart. 


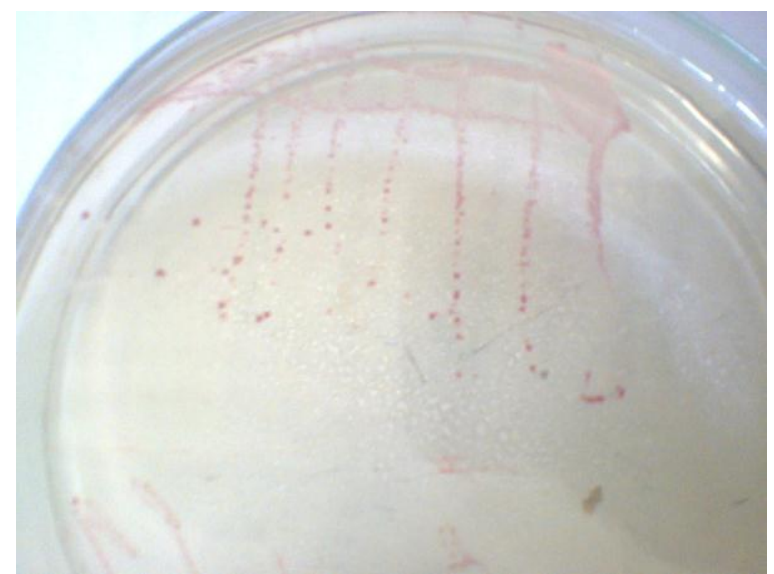

Fig. : St. gallolyticus (Pink colony on S. \& B. medium).

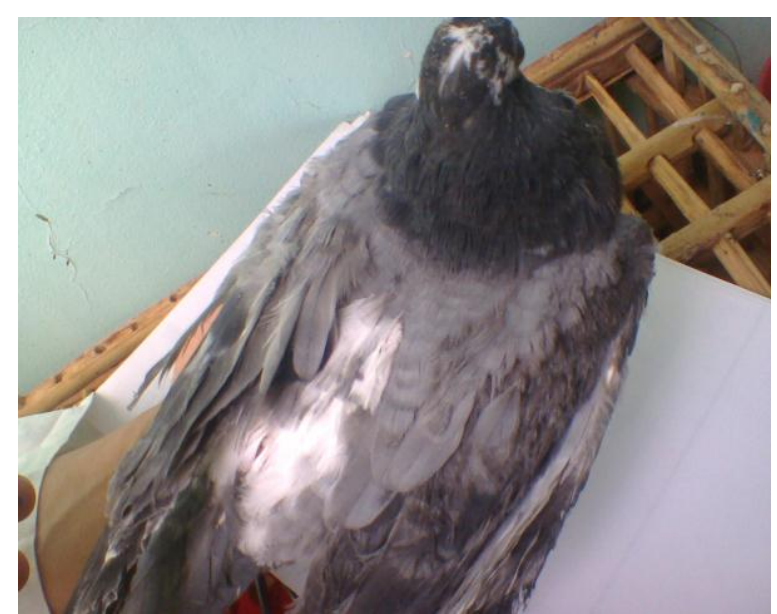

Fig. 3: Drop of right wing due to arthritis caused by St. gallolyticson inoculation.

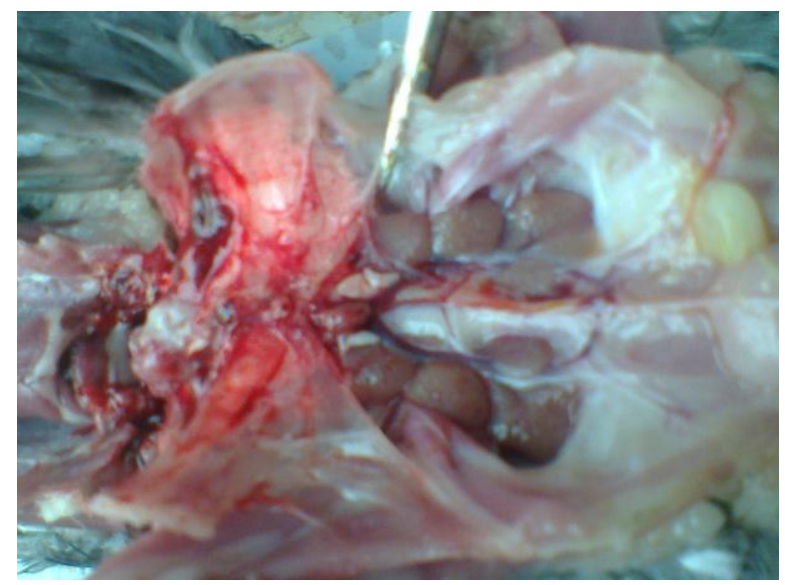

Fig. 5: Enlarged dark kidney as a result of St. gallolyticson inoculation.

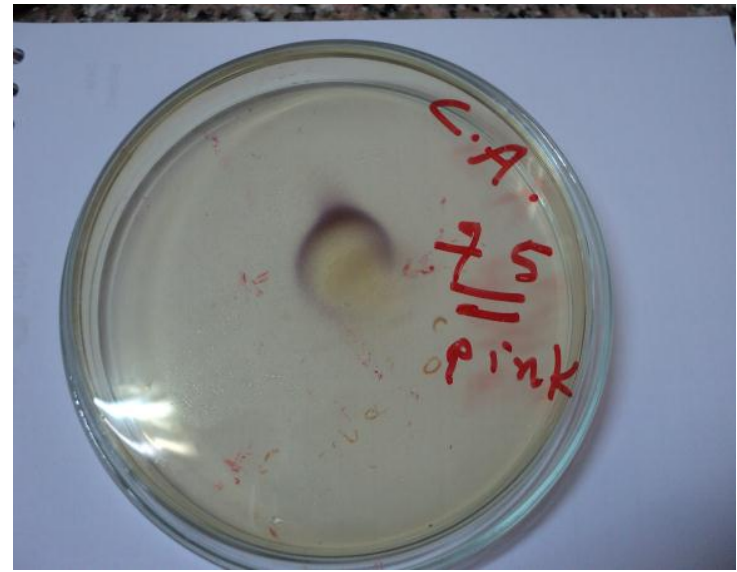

Fig. 2: Amylase test, hallow zone around colony of St. gallolyticson after iodine flooding.

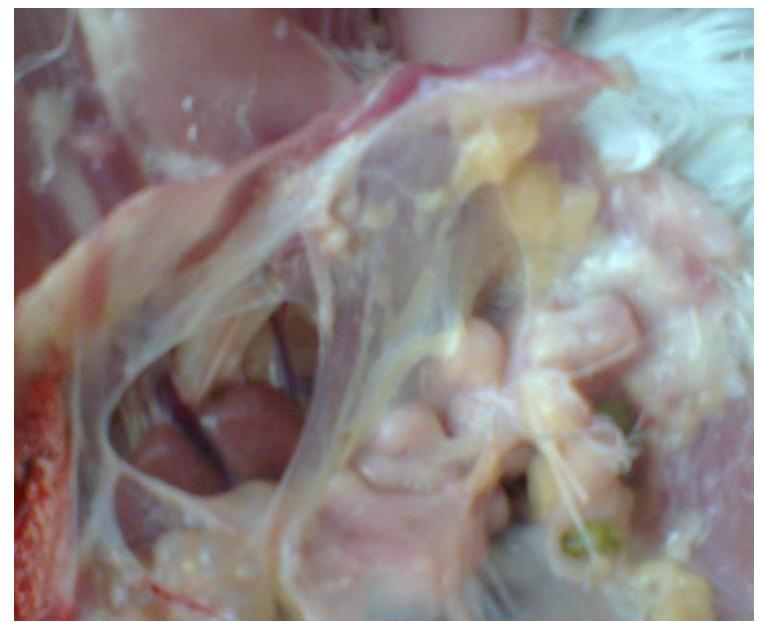

Fig. 4: Cloudy air-sacs as a result of St gallolyticson inoculation.

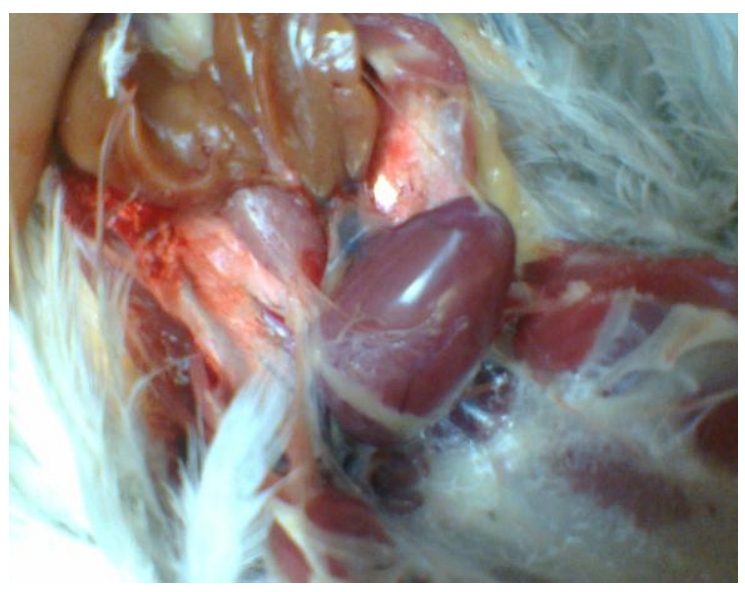

Fig. 6: round due to St. gallolyticson inoculation. 


\section{DISCUSSION}

1- Isolateion of St. gallolyticus strains from the infected homing pigeons: In this study Table (1) records the total incidence of St. gallolyticus in examined pigeon in relation to number of adults and squabs. It revealed isolation of 16 strains of the St. gallolyticus with a percentage of $11.35 \%$. This result nearly was obtained by De Herdt et al. (1994b) and Van der Toorn and Lumeij, (2001) who detected the organism in organs and joints of $10 \%$ of the infected pigeons. The incidence was higher in the examined squabs (13/109) with percentage of $11.93 \%$ than in adults $(3 / 32)$ that isolated with percentage of $9.38 \%$. Streptococcal septicemia is known to exist in pigeons mainly in squabs (Devriese et al., 1990b). Table (2) shows the incidence of St. gallolyticus isolated from 141 infected pigeons in relation to status (diseased or dead) of pigeons. The disease was most prevalent in dead pigeons $(6.38 \%)$ than in diseased ones $(4.97 \%)$ and the organism isolated from diseased squabs $(2.84 \%)$ and adults $(2.13 \%)$ but isolated only from dead squabs $(6.38 \%)$ and not detected in dead adults. De Herdt et al. (1994b) found that, isolation of St. gallolyticus from young pigeons is more higher than that in adults. This may be attributed to low immunity in young pigeons in comparison to that in adults. All isolated strains of St. gallolyticus found following biotype I. The same result was recorded by Mohamed and Abd EllMotelib, (2007).

2- Antimicrobial sensitivity pattern of St. gallolyticus strains isolated from homing pigeons: In-Vitro all isolated strains of St. gallolyticus in the present work were tested for 9 antimicrobial drugs that usually used in the treatment of pigeon diseases using disc diffusion method. The results are recorded in tables (3) \& (4). Table (3) shows that all strains were highly sensitive to flumequine $(100 \%)$. The same percent was recorded by Kimpe et al. (2002a). Also, $100 \%$ of the tested isolates were sensitive to enrofloxacin. High sensitivity of enrofloxacin was also reported by Mohamed and Abd Ell-Motelib, (2007) and with ratio of $88 \%$ sensitivity by Kimpe et al. (2002a) but it's sensitivity was found near to intermediate rang by De Herdt et al. (1993). The isolated strains show high percent of sensitivity to streptomycin $(81.25 \%)$, while the result was found near $50 \%$ by De Herdt et al. (1993). Also, the strains have high rate of sensitivity to florophenicol (81.25\%), chloramphenicol as a same drug group of florophenicol was found sensitive by De Herdt et al. (1993) but with low sensitivity as described by Mohamed and Abd Ell-Motelib, (2007). St. gallolyticus strains were found sensitive to lincomycin and doxycycline with percent of $(75 \%$ for each). The result for lincomycin agrees with these results recorded by De Herdt et al. (1993), but
Kimpe et al. (2002a) recorded 52\% for lincomycin and acquired resistance to oxytetracycline by rate of $85 \%$. Half of the strains $(50 \%)$ were found sensitive to trimethoprim/ sulphmethoxazole, while $100 \%$ resistance was reported by Kimpe et al. (2002a) and Mohamed and Abd Ell-Motelib, (2007). High rate of our isolates resist ampicillin and erythromycin (87.5\% for each). This result is reversed in results of Kimpe et al. (2002a) who detect (100\%) sensitivity to ampicillin and (52\%) to erythromycin, also, Mohamed and Abd Ell-Motelib, (2007) reported high sensitivity to ampicillin and erythromycin. Table (5) shows a multi-drug resistance for 11 out of 16 strains of St. gallolyticus. These strains show resistance for 3 or more than 3 antimicrobial drugs. The difference in results of St. gallolyticus drug sensitivity in different studies may be attributed to the types of drugs that used in pigeon treatment in each study.

\section{3- Experimental infection of healthy pigeons using St. gallolyticus strain.}

I-Intravenous inoculation (I/V) method: The I/V inoculated birds showed signs of disease after 5-7 days post-inoculation in comparison to controls. These signs were prostration, ruffled feathers, loss of body weights, drop in wings due to arthritis (Fig., 3) polyurea and greenish diarrhea. Mortality was not recorded in inoculated birds. Post-mortem lesions observed were cloudy airsacs (Fig., 4), congested liver, enteritis, enlarged kidney with nephritis in some birds (Fig., 5) and kidney atrophy in some few birds plus changes in heart of some birds (rounded heart as in Fig.,6). Re-isolation of inoculated pathogen from experimentally infected birds was successful from throats till 21 day, from hearts of necropised birds till 21 day and from cloacae till 28 day. These results nearly agree with these recorded by Derviese et al. (1990b) but differ with results of Mohamed and Abd Ell-Motalib, (2007) who reported mortality and septicemia in I/V inoculated pigeons but share in changes that occurs in the heart. On the other hand Kimpe et al. (2002b) found that, the birds did not develop clinical disease but shed St. gallolyticus in their faeces after I/V inoculation by low virulence strain of St. gallolyticus.

II- Orally inoculated methods: Birds expressed no deaths and no signs with an exception of slight ruffled feathers and slight loss in weights in two birds. No post-mortem lesions was observed at necropsy except slight cloudiness of air-sacs in one bird. Re-isolation of inoculated pathogen was detected for 14 days post-inoculation in throats and till 21 days from cloacae. Re-isolated from heart was unsuccessful. These results go hand in hand with that of Derviese et al. (1990b) and differ with these results of Mohamed and Abd Ell-Motelib, (2007), 
they reported body weight losses, greenish diarrhea and lameness.

Conclusion: Streptococcus gallolyticus infection in pigeons is a septicemic disease especially in squabs. The disease infect about $11.35 \%$ of examined pigeons. This pathogen shows gradual increase in multi-drug resistance for the traditional antimicrobial agents. So, attention must be taken in consideration to multi-drug resistance development.

\section{REFERENCES}

Baele, M.; Devriese, L.A.; Butaye, P. and Haesebrouck, F. (2002): Composition of enterococcal and streptococcal flora from pigeon intestines. Journal of Applied Microbiology, 92: 348-351.

Barnes, E.M. (1958): The effect of antibiotic supplements on the faecal streptococci (Lancefield Group D) of poultry. British Veterinary Journal, 144: 333-344.

Chadfield, M.S.; Christensen, J.P.; Decostere, A.; Christensen, H. and Bisgaard, M. (2007): Geno- and Phenotypic Diversity of Avian Isolates of Streptococcus gallolyticus subsp. gallolyticus (Streptococcus bovis) and Associated Diagnostic Problems. Journal of Clinical Microbiology, 45 (3): 822-827.

De Herdt, P.; Haesebrouck, F.; Devriese, L.A. and Ducatelle, R. (1992a): Biochemical and antigenic properties of Streptococcus bovis isolated from pigeons. J. Clin. Microbiol., 30: 2432-2434.

De Herdt, P.; Desmidt, M.; Haesebrouck, F.; Ducatelle, R. and Devriese, L.A. (1992b): Experimental Streptococcus bovis infections in pigeons. Avian Dis. 36: 916-925.

De Herdt, P.; Devriese, L.A.; De Groote, B.; Ducatelle, R. and Haesebrouck, F. (1993): Antibiotic treatment of Streptococcus bovis infections in pigeons. Avian Pathology, 22: 605-615.

De Herdt, P.; Ducatelle, R.; Haesebrouck, F.; Devriese, L.A.; De Groote and Roels, S. (1994a): An unusual outbreak of Streptococcus bovis septicaemia in pigeons (Cofumba livia).Vet. Rec., 134: 42-43.

De Herdt, P.; Haesebrouck, F.; Devriese, L.A. and Ducatelle, R. (1994b): Prevalence of Streptococcus bovis in racing pigeons. Veterinary Quarterly, 16 (2): 71-74.

Devriese, L.A.; Gevaert, D. and Ceysses, K. (1990a): Characteristics of Streptococcus bovis Associated with Pigeons. Avian Pathology, 19: 425-428.

Devriese, L.A.; Uyttebroek, E.; Gevaert, D.; Vandekerckhove, P. and Ceysses, K. (1990b):
Streptococcus bovis infection in pigeons. Avian Pathology, 19: 429-434.

Devriese, L.A.; Pot, B. and Collins, M.D. (1993): Phenotypic identifcation of the genus Enterococcus and differentiation of phylogenetically distinct enterococcal species and species groups. Journal of Applied Bacteriology, 75: 399-408.

Devriese, L.A.; Vandamme, P.; Pot, B.; Vanrobaeys, M.; Kersters, K. and Haesebrouck, F. (1998): Differentiation between Streptococcus gallolyticus strains of human clinical and veterinary origins and Streptococcus bovis strains from the intestinal tracts of ruminants. Journal of Clinical Microbiology 36: 35203523.

Harrison, A.P. and Hansen, P.A. (1950): The bacterial flora of the cecal faeces of healthy turkeys. Journal of Bacteriology. 50: 197-210.

Kimpe, A.; Decostere, A.; Martel, A.; Haesebrouck, F. and Devriese, L.A. (2002a): Prevalence of antimicrobial resistance among pigeon isolates of Streptococcus gallolyticus, Escherichia coli and Salmonella enterica serotype typhimurium. Avian Pathology, 31: 393-397.

Kimpe, A.; Hermans, K.; De Herdt anb Haesebrouck, F (2002b): Failure of low virulence Streptococcus gallolyticus serotype 1 strain to immunize pigeons against streptococcosis. Avian Pathology, 31: 421423.

Kimpe, A.; Decostere, A.; Hermans, K.; Mast, J. and Haesebrouck, F. (2003): Association of Streptococcus gallolyticus strains of high and low virulence with the intestinal tract of pigeons. Avian Diseases, 47: 559-565.

Madej, E. (1961): Obserwacje nad streptokokkaza golebi. Medycyna Weterynaryjna, 17: 713715.

Mohamed, H.A. and Abd El- Motelib, T.Y. (2007): "Studies on gram-positive organisms in sick pigeons. Assiut Vet. Med. J., 53 (114): 280290.

Mohamed, I.E.; Gehan, H. El-Sakkar and Magda, M.M. Moursi (2009): Pathological studies on pigeon trichomoniasis with reference to the associated bacteria. Egypt. J. Comp. Path. \& Clinic. Path., 22 (2): 67-87.

Mundt, J.O. (1963): Occurrence of Enterococci in animals in a wild environment. Applied Microbiology, 11: 136-140.

NCCLS "National Committee for Clinical Laboratory Standards" (2001): Performance standards for antimicrobial susceptibility testing. Supplement M100-S11. Villanova, PA, USA.

Parker, M.T. (1978): The pattern of streptococcal disease in man. In: Streptococci, pp. 71-106. 
Edited by Skinner, F.A. and Quesnel, L.B. London: Academic Press.

Van der Toorn, F. and Lumeij, J.T. (2001): Streptococcus gallolyticus infections in racing pigeons, a literature review. Tijdschr Diergeneeskd., 126(3): 66-71.
Vanrobaeys, M.; De Herdt, P.; Haesebrouck, F.; Ducatelle, R. and Devriese, L.A. (1996): Secreted antigens as virulence associated markers in Streptococcus gallolyticus strains from pigeons. Veterinary Microbiology, 53: 339-348.

\section{عدوى بكتيريا المكورات السبحية نوع جالوليتيكس في الحمام: التأثير المرضى والحساسية للمضادات الحيوية}

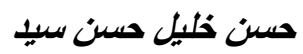

Email: hassankhalil22@yahoo.com

تعتبر الاصابة بعدوى بكتيريا المكورات السبحية نوع جالوليتيكس من أهم الأمراض البكتيرية التى تسبب تسمم دموي في الحمام

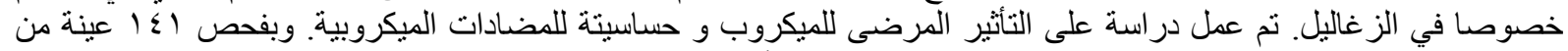

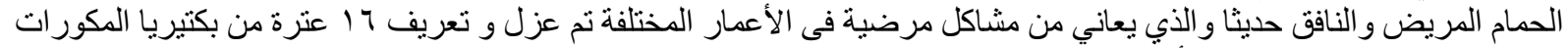

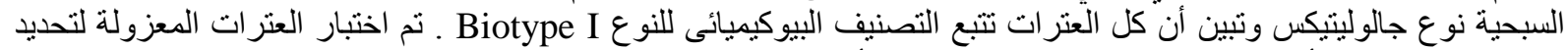

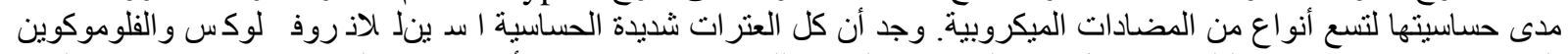

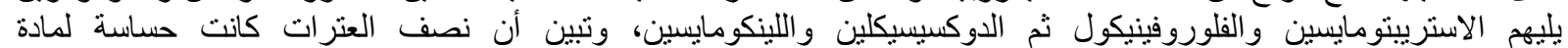

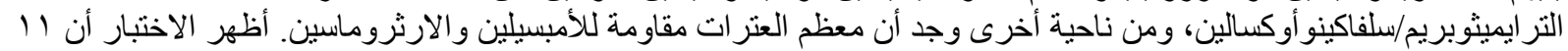

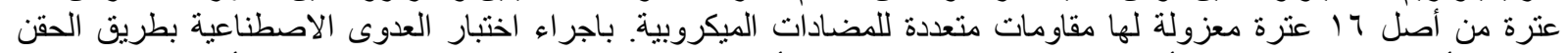

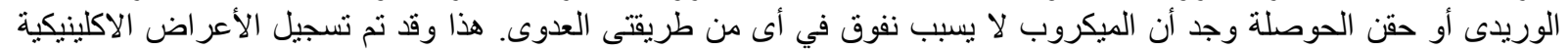

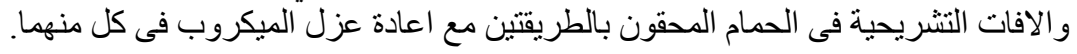

